\title{
Technique of transurethral needle core biopsy to confirm invasive bladder cancer staging
}

\author{
Piotr Chłosta', Artur A. Antoniewicz², Tomasz Szopiński², Jakub Dobruch², Andrzej Borówka²
}

1Department of Urology, Institute of Oncology, Kielce, Poland

2Department of Urology, Centre of Postgraduate Urology Education, Postgraduate University, Warsaw, Poland

Submitted: 23 April 2009

Accepted: 4 May 2009

Arch Med Sci 2010; 6, 3: 388-392

DOI: $10.5114 /$ aoms.2010.14260

Copyright @ 2010 Termedia \& Banach
Corresponding author:

Piotr L. Chłosta,

$M D, P h D, F E B U$

Department of Urology

Institute of Oncology

Artwinskiego 3

25-734 Kielce, Poland

Phone: +48 413674774

Fax: +48 413674773

E-mail:

piotr.chlosta@onkol.kielce.pl

\begin{abstract}
Introduction: Transurethral, cystoscopically-guided needle core biopsy (TUcoreBxBT) seems to be a less invasive diagnostic method than transurethral resection (TURBT) offering a simple way to confirm cancer infiltration of the bladder. The aim of this study was to assess the technique of TUcoreBxBT in the diagnosis of bladder cancer infiltrating the detrusor muscle.

Material and methods: In every 96 pts the suspicion of invasive bladder cancer (IBC) was evaluated on the basis of radiological examinations, cystoscopy and bimanual examination. TUcoreBXBT were performed using a rigid cystoscope with a direct working channel and tru-cut automatic (COOK Quick-Core ${ }^{\circledR}$ BiopsyNeedle) $18 \mathrm{G} / 480 \mathrm{~mm}$ needle or self construction tru-cut $16 \mathrm{G} / 400 \mathrm{~mm}$ needle, adapted to work with a standard biopsy gun. At least three cores were taken in each patient, followed by regular TURBT.

Results: There were no complications of the bladder biopsy procedure. The average size of cores was $15 \mathrm{~mm}(8-17 \mathrm{~mm})$. In every case TUcoreBxBT revealed muscle infiltration and was in agreement with all microscopic examinations of TURBT.

Conclusions: TUcoreBxBT in cases of clear suspicion of invasive bladder cancer is a simple, short and safe procedure which makes it possible to collect reliable material for microscopic examination. TUcoreBxBT is less invasive than standard TURBT only in diagnosis and staging of invasive tumours, and seems to be effective in selected cases to confirm malignancy before radical cystectomy.
\end{abstract}

Key words: invasive bladder cancer, tru-cut biopsy, staging.

\section{Introduction}

The most fundamental tool used to distinguish superficial and muscle invasive bladder cancer $(\mathrm{BCa})$ is properly performed transurethral resection of the bladder tumour (TURBT). As is widely accepted, in TURBT material should be taken separately from the tumour, its margins and the bottom $[1,2]$. Diagnosis of invasive bladder cancer (IBC) is usually not difficult. Infiltration of bladder detrusor revealed by histopathological examination $(\mathrm{H}-\mathrm{P})$ of the TURBT specimen differentiates the BCa character. However, in some patients with advanced disease, clinical signs known before TURBT may strongly suggest the presence of muscle invasive tumour. These are the results of imaging tools, bimanual examination and cystoscopy [3, 4]. Prominent infiltration may be expressed in particular by hydronephrosis, which may result from deep infiltration of the intramural part of the ureter 
and may be found in ultrasound scan of the abdomen (TAUS), intravenous urography (IVU) or computed tomography (CT) [5]. Transurethral resection of the bladder tumour is then carried out to confirm the invasive character of $\mathrm{BCa}$, but histopathological examination may reveal only cancer cells without muscle tissue. Nevertheless, imaging procedures, especially $C T$, carried out before TURBT allow us to anticipate the presence of IBC.

The question is whether there is any possibility of TURBT replacement in patients who present with strong suspicion of invasive character of bladder tumour revealed by clinical signs, especially by TAUS, IVU or CT, and who are potential candidates for radical treatment.

The aim of this study is to present the technique of bladder tumour transurethral core biopsy (TUcoreBxBT) in the diagnosis of bladder cancer infiltrating detrusor muscle, which can replace diagnostic TURBT of IBC patients.

\section{Material and methods}

Ninety-six patients (87 men and 9 women) aged between 43 and 79 years (mean age 65 years), who presented with locally advanced, extensive bladder tumour suggested by TAUS and CT, were included in the study. In 72 patients, the above-mentioned imaging examinations were carried out due to haematuria only, whereas there were another 14 patients with haematuria and lower urinary tract symptoms (frequency, painful micturition; LUTS), 1 patient with LUTS only and 9 experienced lumbar pain. TAUS, IVU and CT revealed unilateral or bilateral hydronephrosis associated with bladder tumour in 51 patients. All patients were potential candidates for radical cystectomy if the invasive character of the tumour could be confirmed. The patients were subjected to TUcoreBxBT just before the standard TURBT. The procedures were performed under local spinal anaesthesia and were preceded by urinary bladder and urethra detailed endoscopic examination. Tru-cut 16 G, $400 \mathrm{~mm}$ in length (self-made) or $18 \mathrm{G}, 480 \mathrm{~mm}$ in length (COOK Quick-Core ${ }^{\circledR}$ Biopsy-Needle) needles put into the biopsy gun (Bard ${ }^{\circledR}$ Magnum ${ }^{\circledR}$ Instrument MG1522) were used to carry out biopsy of the bladder tumour (Figure 1). The needle was speared superficially into the tumour and the biopsy gun was released (Figure 2). At least three cores were taken in each patient, followed by regular TURBT. Pathological assessment of tissue cores and TURBT specimens was done after standard preparation and haematoxylin-eosin staining. In all patients it was possible to take tissue cores. All tumours had exophytic character. The most 'favourable' location of the tumour in terms of the biopsy procedure was the posterior and lateral walls of the bladder.

All patients were diagnosed with IBC and subjected to radical cystectomy. The specimens were then routinely evaluated. Comparison of histopathological assessment of tissue cores, TURBT and radical cystectomy specimens was done to evaluate the clinical significance of TUcoreBxBT. The type and the grade of the tumour were analysed. All data were collected after local ethics committee approval and all patients signed informed consent previously accepted by the committee.

\section{Results}

The quality of all tissue cores gained by TUcoreBXBT was sufficient to carry out a reliable histopathological assessment. Length of tissue cores ranged from $8 \mathrm{~mm}$ to $17 \mathrm{~mm}$ (mean length $15 \mathrm{~mm}$ ). Due to the bladder tumour biopsy, transitional cell carcinoma (TCC), squamous cell carcinoma (SCC) and adenocarcinoma were diagnosed in 92, 3 and 1 patient, respectively. In 12 patients among those with TCC, SCC transformation was also found. TCC grade was G2 and G3 in 31 and 49 patients, respectively. SCC and AC grades were assessed as G2 in all cases. Among patients diagnosed with TCC with SCC transformation, G2
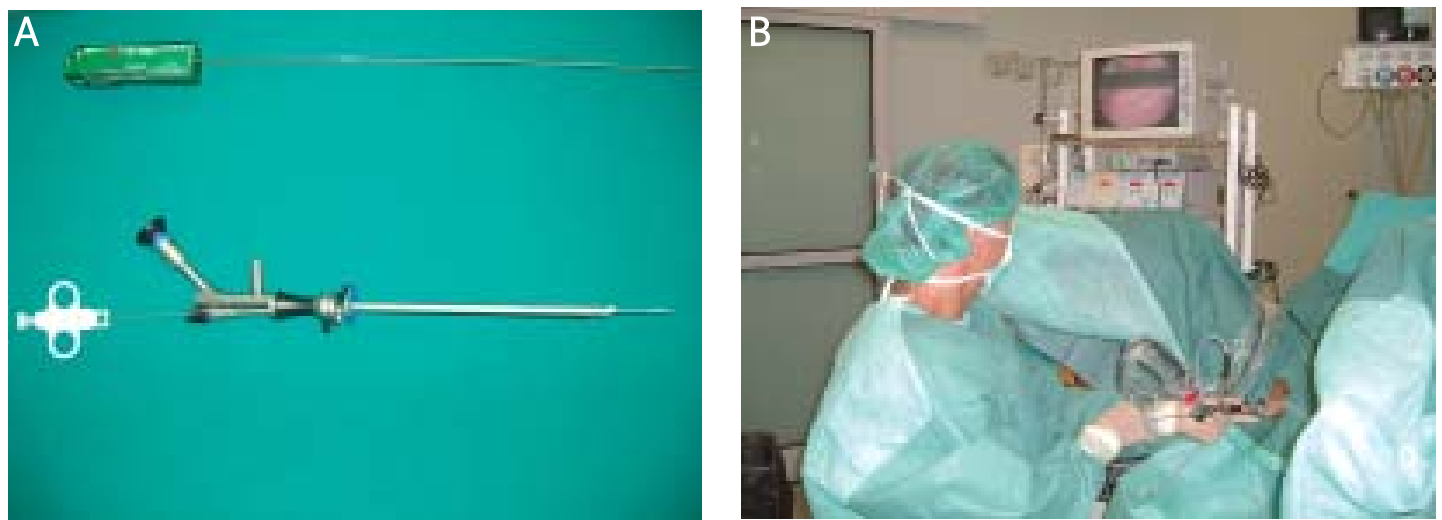

Figure 1. Instruments for transurethral, cystoscopically-guided needle core biopsy (TUcoreBxBT) (A) and the way of their usage (B) 

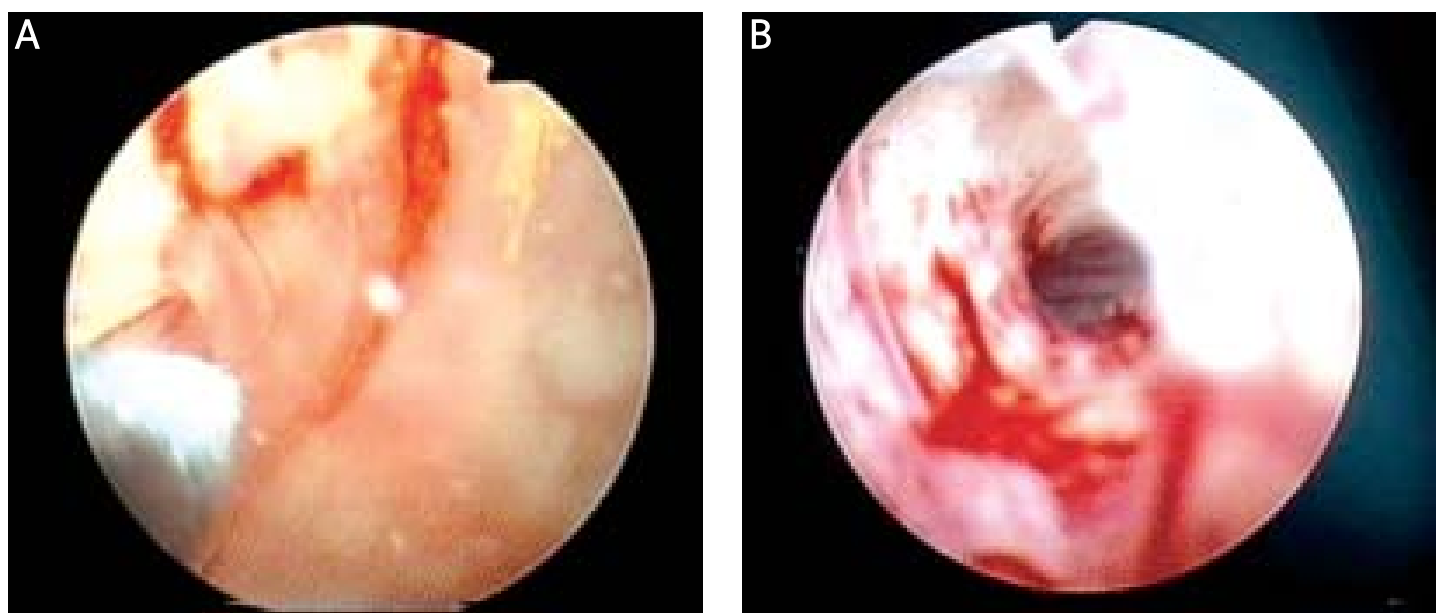

Figure 2. Endoscopic view of transurethral, cystoscopically-guided needle core biopsy (TUcoreBxBT). A - the needle before puncturing the right bladder wall tumour, B - the status after the biopsy

grade in 2 cases and $\mathrm{G} 3$ grade in 10 cases were found (Table I). In all patients muscle infiltration was revealed by histopathological examination of tissue cores (Figure 3). Histopathological analysis of TURBT specimens was in complete accordance with previous tissue core assessment in terms of the type and the grade of bladder cancer. Muscle invasion by cancer cells was found in all specimens. There were no complications specifically associated with the biopsy procedure. There was also no need for coagulation of the 'spear area' on the surface of the tumour.

\section{Discussion}

The fundamental tool used to evaluate BCa character (to differentiate between superficial and muscle invasive bladder tumour) is properly carried out TURBT and histopathological examination of the specimen $[1,2]$. Clinical staging by imaging tools

Table I. The results of histopathological examination of transurethral bladder tumour biopsy cores (TUcoreBxBT)

\begin{tabular}{|lccc|}
\hline $\begin{array}{l}\text { Histopathological type } \\
\text { of cancer }\end{array}$ & Grading & $\begin{array}{c}\text { Number/percentage } \\
\text { of patients }\end{array}$ \\
\hline TCC & G2 & 31 & $32.3 \%$ \\
\cline { 2 - 4 } & G3 & 49 & $51.0 \%$ \\
\hline TCC/SCC & G2 & 2 & $2.0 \%$ \\
\cline { 2 - 4 } & G3 & 10 & $10.5 \%$ \\
\hline SCC & G2 & 3 & $3.2 \%$ \\
\hline G3 & - & - \\
\hline AC & G2 & 1 & $1.0 \%$ \\
\hline Total & G3 & - & - \\
\hline
\end{tabular}

$A C$ - adenomatous cancer, SCC - squamous cell cancer, TCC - transitional cell cancer, $G$ - grading is not unquestionable and plays only an additional role [6]. Transurethral resection of the bladder tumour is a rather invasive procedure and is associated with substantial risk of complications, especially in regard to extensive bladder tumours [7]. In some patients, muscle infiltration of bladder tumour may be suspected during cystoscopy (plane tumour with wide base and no flocks on its surface, 'inflexibility' of tumour infiltrating the bladder wall). Hence, collecting sufficient tissue material to assess the quantity of muscle tissue in a less invasive manner is required before eventual radical cystectomy. It seems that TUcoreBxBT is a favourable option in patients who present with bladder tumour and who are highly suspected to have muscle involvement due to imaging procedures (TAUS, IVU) carried out before cystoscopy [8].

There were no complications specifically associated with the transurethral core biopsy procedure. It is not possible to exclude such a risk because the biopsy was followed by regular TURBT, which would mask their presence. However, one would not envisage major complications with a few punctures. The risk of cancer cell spread as a consequence of TUcoreBxBT remains to be elucidated. However, it does not preclude carrying out prostate biopsy in men with high suspicion of prostate cancer [9]. It is conceivable that the risk of implantation of cancer cells outside the bladder wall during TUcoreBxBT should not be greater than in the case of extensive TURBT.

The idea of using TUcoreBxBT in the diagnosis of muscle invasive tumours is unique. Transcutaneous needle core biopsy under ultrasound control and transurethral core biopsy using a nephroscope carried out in patients with locally advanced bladder tumour subjected to neoadjuvant treatment were presented by Hoshi et al. [10]. It 

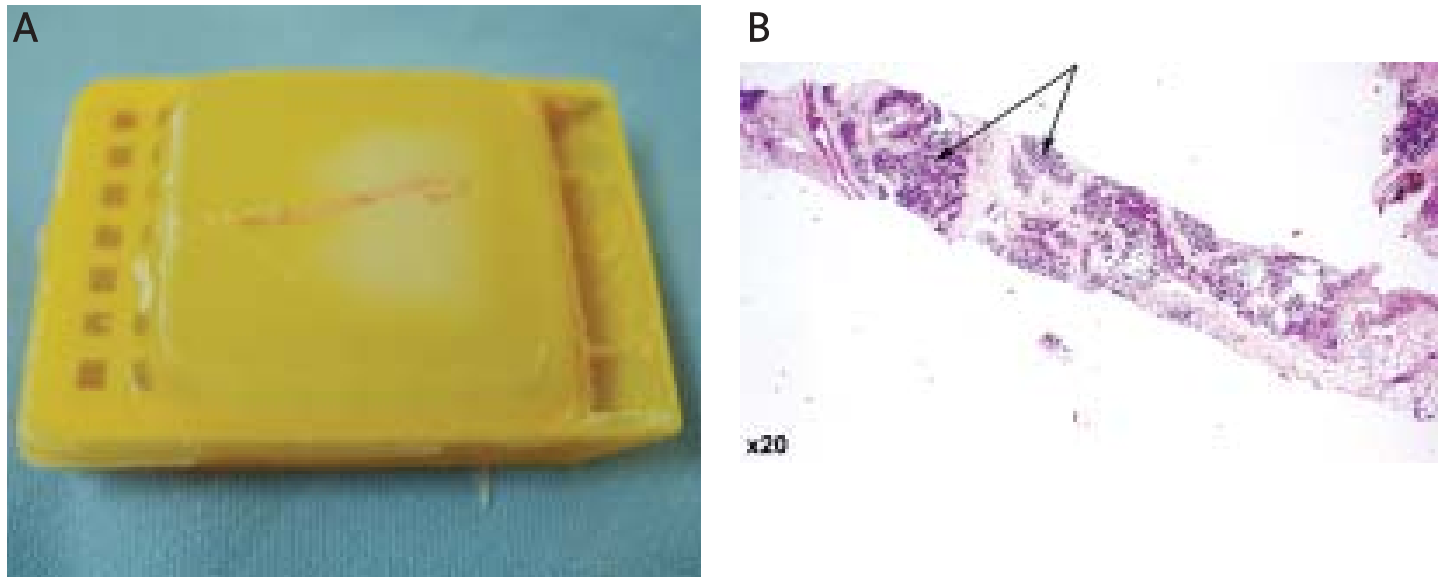

Figure 3. The bladder tumour biopsy core prepared for histopathological examination (A), histopathological view of the invasive bladder cancer TUcoreBxBT specimen. Arrows indicate cancer cells between detrusor muscle tissue (enlarged 20x, H/E] (B)

was suggested that the biopsy allowed collection of enough tissue material to evaluate the tumour stage and the treatment results. Malmstrom et al. introduced transcutaneous bladder core biopsy carried out under CT control in patients who underwent neoadjuvant chemotherapy due to $\mathrm{BCa}$ in order to collect valuable amounts of tissue material [11].

The results do not suggest that diagnostic TURBT would be replaced by TUcoreBxBT in all patients presenting with $\mathrm{BC}$. It would be very difficult to find carcinoma in situ. TUcoreBxBT would not be applied in cases of superficial BCa. On the other hand, in cases of extensive, solid, muscle infiltrating bladder tumours it allows for quick, cost-effective, efficient and less invasive collection of tissue material for histopathological examination and qualification for radical therapy. The biopsy carried out in patients subjected to TURBT carried out just to confirm tumour invasiveness before radical cystectomy has obvious advantages: reduced duration of the procedure, lower probability of bladder perforation and bleeding, lack of perivesical lesions observed after TURBT and the possibility of carrying out the procedure under intravenous anaesthesia and in an out-patient setting. Therefore, it is reasonable to suggest that TUcoreBxBT, which is supposed to invade the muscle tissue, will simplify the diagnostic procedure aimed at tumour staging before radical therapy and make it easier and also less invasive.

In conclusion, transurethral core biopsy of bladder tumour is indicated only in patients with large and highly suspected muscle invasive characteristics of bladder cancer. The biopsy would serve to confirm the clinical data before planned radical cystectomy. There are enough clinical data to know that the tumour infiltrates deeply into the bladder wall, but to carry out cystectomy, histological confirmation is still needed. In such cases, instead of the relatively invasive TURBT, the biopsy and a few tissue cores may be sufficient to reveal bladder detrusor involvement. In patients with less advanced disease, the biopsy would not bring any benefit.

Endoscopic transurethral needle core bladder tumour biopsy (TUcoreBxBT) allows collection of sufficient amounts of tissue material for histopathological confirmation of detrusor muscle infiltration.

TUcoreBxBT bladder tumour biopsy carried out under cystoscopic control is short lasting, efficient, safe, easy to perform and less invasive than standard transurethral resection of bladder tumour (TURBT) carried out in cases of extensive invasive bladder cancer (IBC).

\section{References}

1. Messing EM, Young TB, Hunt VB, et al. Comparison of bladder cancer outcome in men undergoing hematuria home screening versus those with standard clinical presentations. Urology 1995; 45: 387-97.

2. Kolozsy Z. Histopathological 'self control' in transurethral resection of bladder tumors. Br J Urol 1991; 67: 162-4.

3. Oesterlinck W, Lobel B, Jakse G, et al. European Association of Urology (EAU) Working Group on Oncological Urology Guidelines on bladder cancer. EAU 2005; 3-30

4. Husband JE, Olliff JF, Williams MP, et al. Bladder cancer: staging with CT and MR imaging. Radiology 1989; 173: 435-40.

5. Chłosta P, Antoniewicz AA, Szopiński T, et al. Ocena porównawcza przydatności ultrasonografii przezpowłokowej tomografii komputerowej oraz jądrowego rezonansu magnetycznego do oceny stopnia zaawansowania raka pęcherza moczowego $u$ chorych poddanych cystektomii radykalnej [Polish]. Urol Pol 2004; 2: 20-4.

6. Voges GE, Tauschke E, Stockle M, et al. Computerized tomography: an unreliable method for accurate staging of bladder tumors in patients who are candidates for radical cystectomy. Urology 1989; 142: 972-4. 
7. Herr HW. Surgical factors in the treatment of superficial and invasive bladder cancer. Urol Clin North Am 2005; 32: 157-64.

8. Chłosta P, Szopiński T, Antoniewicz AA, et al. Clinical significance of transurethral tru-cut biopsy in confirmation of bladder tumor invasive character. Int J Urol 2008; 15: 804-8.

9. Sachs MD, Chan T, Solomon SB, Konig F, Schoenberg M. Diagnostics and diagnostic pitfalls in urothelial bladder cancer. In: Droller MJ (ed.). Urothelial tumors. BC Decker Inc, London 2004; 73-91.

10. Hoshi S, Ono K, Suzuki K, et al. Trans-urethral whole layer core biopsy for detection of residual tumor after neoadjuvant therapy in invasive bladder cancer. Urol Oncol 2001; 6: 85-9.

11. Malmstrom PU, Lonnemark M, Busch C, et al. Staging of bladder carcinoma by computer tomography-guided transmural core biopsy. Scand J Urol Nephrol 1993; 27: 193-8. 